\title{
Role of partial hepatectomy on Capillaria bepatica-induced hepatic fibrosis in rats
}

\author{
Papel da hepatectomia parcial sobre a fibrose septal do fígado \\ induzida pela Capillaria bepatica em ratos
}

\author{
Carolina Cincurá Silva Santos ${ }^{1}$, Záira Onofre-Nunes ${ }^{1}$ and Zilton Araujo Andrade ${ }^{1}$
}

\begin{abstract}
It is known that hepatic fibrosis may regress following partial hepatectomy, since the hepatic parenchyma regenerates very rapidly, but not the excess of fibrous tissue. The present study evaluated this hypothesis by observing the behavior of systematized septal fibrosis induced by either 30 or 90-day-old Capillaria hepatica infection, in rats subjected to partial hepatectomy. The results revealed that the morphology of the fibrosis was unaffected, but its relative quantity within the microscope field appeared significantly decreased, as a consequence of the increased liver tissue mass following regeneration.
\end{abstract}

Key-words: Hepatectomy. Fibrosis. Capillaria hepatica.

\section{RESUMO}

Sabe-se que a fibrose hepática pode sofrer uma redução em seqüência uma hepatectomia parcial, uma vez que o parênquima hepático se regenera muito rápido, mas não o excesso de tecido fibroso. O presente trabalbo avalia esta hipótese ao observar como se comporta a fibrose septal sistematizada induzida pela Capillaria hepática no rato, após infecção de 30 ou 90 dias de duração, em animais submetidos à hepatectomia parcial. Os resultados revelaram que a fibrose em si mesma não foi afetada na sua morfologia, mas a sua quantidade relativa apareceu diminuída significativamente no campo microscópico como conseqüiência do aumento da massa de tecido hepático pós-regeneração.

Palavras-chaves: Hepatotectomia. Fibrose. Capillaria hepatica.

The extraordinary regenerative capacity of the liver is well documented. Removal of up to $60 \%$ of the normal liver mass is followed by complete restoration of its volume and histology within a few days ${ }^{2}$. Since restoration of liver size following partial hepatectomy involves both the parenchyma and its supporting vascular-connective stroma, there has been some expectation that a diseased liver would regenerate with some structural improvement. It has been said that, in some situations, partial hepatectomy would appear to favor reversibility of experimental cirrhosis $^{8}$.

Most experimental investigations concerning regeneration in diseased livers have been performed using the model of carbon tetrachloride-induced cirrhosis in rats ${ }^{7}$. However, this model has several disadvantages. The stage of cirrhosis may vary in different animals within the same experimental group, the pathological process is soon altered following discontinuation of drug administration and the mortality rate is quite high $^{714}$. Furthermore, cirrhosis is a complex pathological condition, involving several types of vascular and enzymatic changes ${ }^{6}$.
To obviate such inconveniences, a new model of systematized septal fibrosis, which occurs in rats infected with the helminth Capillaria bepatica ${ }^{131112}$, was used in the present investigation in order to test the effects of partial hepatectomy on diseased livers. Systematized septal fibrosis associated with rat capillariasis becomes well established around the $17^{\text {th }}-20^{\text {th }}$ day following infection, and then fully stabilizes a few days later. Thereafter, it remains stable for over a year ${ }^{\mathbf{1 1}}$. The fibrosis characteristically alters the liver morphology but causes little impairment to its physiology ${ }^{\mathbf{1 0}}$. Therefore, it seemed to be a suitable experimental model for testing the effects of partial hepatectomy on fibrosis, and for testing how the presence of fibrosis would interfere with regeneration.

\section{MATERIAL AND METHODS}

Animals and experimental groups. Twenty-five healthy adult albino Swiss rats of both sexes, weighing 200-240g, were used. They were maintained in individual metal boxes in a well-

\footnotetext{
1. Laboratório de Patologia Experimental, Centro de Pesquisas Gonçalo Moniz, Fundação Oswaldo Cruz, Salvador, BA, Brasil.

Address to: Zilton Araujo Andrade. Lapex/CPGM/FIOCRUZ. Rua Valdemar Falcão 121, 40295-001 Salvador, BA.

e-mail: zilton@cpqgm.fiocruz.br

Recebido para publicação em: 15/05/2007

Aceito em: 17/08/2007
} 
ventilated room, with free access to a commercially-produced balanced diet and water. They were divided into five groups, with five animals each, as follows:

Group I. Early infection: animals subjected to partial hepatectomy 30 days after Capillaria hepatica infection.

Group II. Late infection: animals subjected to partial hepatectomy 90 days after Capillaria bepatica infection.

Group III. Non-infected controls: normal rats subjected to partial hepatectomy.

Group IV. Control for early infection: non-operated animals with 30-day-old Capillaria hepatica infection. Group V. Control for late infection: non-operated animals with 90-day-old Capillaria hepatica infection.

Capillaria hepatica infection. The animals were infected with 600 embryonated eggs of Capillaria hepatica that were suspended in saline and administered by gavage. The eggs had been isolated from the livers of experimentally infected mice through homogenization in saline followed by repeated washing and sedimentation. The cleaned isolated eggs were maintained in a humidified Petri dish at $25-28^{\circ} \mathrm{C}$ for a period of 28 days, for embryonation.

Surgical procedures. When the animals underwent partial hepatectomy, they were first anesthetized using $2.5 \mathrm{ml}$ of ketamine plus $0.5 \mathrm{ml}$ of xylazine, in $1 \mathrm{ml}$ of saline (0.85\%). Under strict aseptic conditions, the abdomen was opened at the midline, and the left lateral and medial lobes of the liver were removed following ligature of their vascular pedicles. These lobes corresponded to $50-60 \%$ of the total liver mass ${ }^{7}$. No surgical mortality occurred. Thirty days after partial hepatectomy, all the animals were sacrificed using an intraperitoneal overdose of $2 \mathrm{ml}$ of thiopental.

Histology. Fragments of liver tissue taken both at hepatectomy and at autopsy were fixed in $10 \%$ neutral formaldehyde and embedded in paraffin. The 5-micrometer sections obtained were stained routinely with hematoxylin and eosin, and with the picrosirius method for collagen. To evaluate the fibrosis, the sections were subjected to both semi-quantitative and quantitative morphometric methods.

The semi-quantitative evaluation was done on picrosirius red-stained slides. The fibrosis was considered mild $(+)$ when approximately half of the microscopic fields (100x magnification) were free from septal fibrosis and severe $(+++)$ when a morphological state of cirrhosis was present. It was considered moderate $(++)$ in intermediate situations between these two endpoints, as can be seen in Figure 1A, B and C.

The quantitative morphometric analysis was also done on picrosirius-stained slides. From each animal, five $0.7 \mathrm{~mm}^{2}$ quadrants taken at random from the liver slides were measured. The red-stained area of fibrosis was demarcated with a cursor and evaluated by means of a computerized system (Axion Vision 3.1) under a microscope (Carl Zeiss Vision $\mathrm{GmbH}$ ). The results were expressed as absolute values $\left(\mathrm{mm}^{2}\right)$.

Statistical analysis. The Mann Whitney and Wilcoxon non-parametric tests were used with a computerized system (GraphPad Prism, version 3.00). $\mathrm{P}<0.05$ was considered statistically significant.

\section{RESULTS}

Comparison of the microscope images of the livers from the two experimental groups of animals with recent infection (Group I, with hepatectomy, and its corresponding control, Group IV) showed essentially the same findings. These consisted of focal parasitic lesions formed around dead and dying worms and their eggs, and a systematized form of septal fibrosis. The septal fibrosis delimited irregular portions of the hepatic parenchyma, which exhibited plates of one cell in thickness, even in areas with a nodular appearance, in which a cirrhotic pattern appeared simulated. The semi-quantitative evaluation considered the fibrosis to be predominantly severe $(3+$; Figure $1 \mathrm{~A})$, with some areas where the septa were less frequent (moderate degree, $2+$; Figure 1B). Among the animals subjected to hepatectomy and examined 30 days later, the septal fibrosis appeared more spaced, leaving large areas of uninvolved hepatic parenchyma appropriate control, but more so for the group with recent infection (predominantly 1+), than for the non-operated infected control (predominantly $2+$ ).

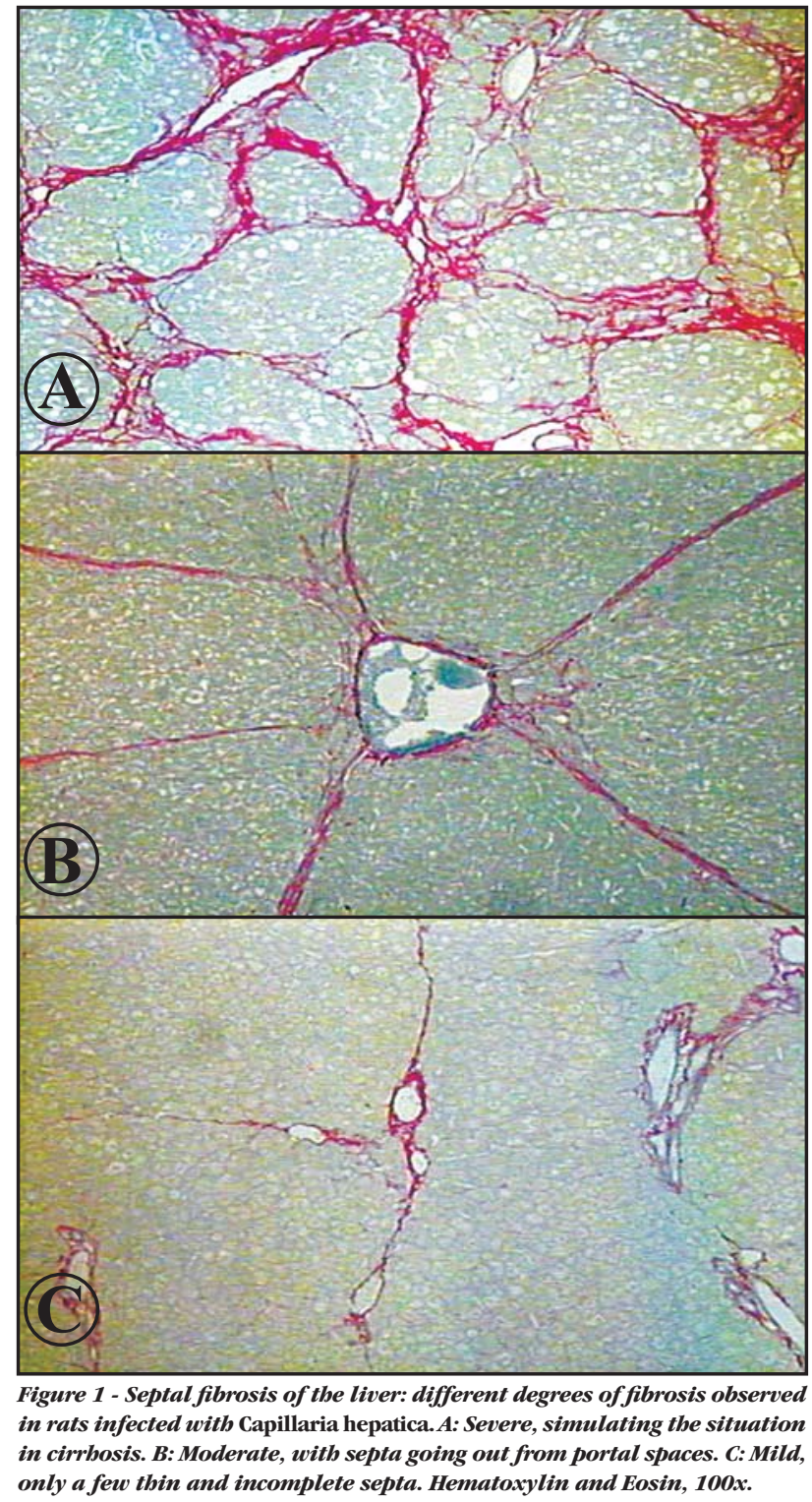


Ninety days after infection (Group II and its control, Group V), the focal parasitic lesions showed a considerable degree of resolution or modulation in both groups. The lesions were smaller and well-delimited by a fibrous capsule, with a central area of necrosis and calcification that was mixed with many parasite eggs. No morphological differences were noted when the focal parasitic lesions from these two groups were compared. Septal fibrosis was present with its usual distribution, but the proportion of fibrous septa in relation to liver parenchyma had diminished considerably, as can be seen in Figure 2, which depicts the morphometric evaluation.

The results from the morphometric evaluation demonstrated that there was a statistically significant difference in fibrosis between Group I and its control, Group IV ( $p=0.007)$, as depicted in Figure 2. Comparison between Group II and its control, Group V, also revealed a statistically significant difference $(p=0.03)$. The mortality rate was quite low, with no differences registered among the various groups.

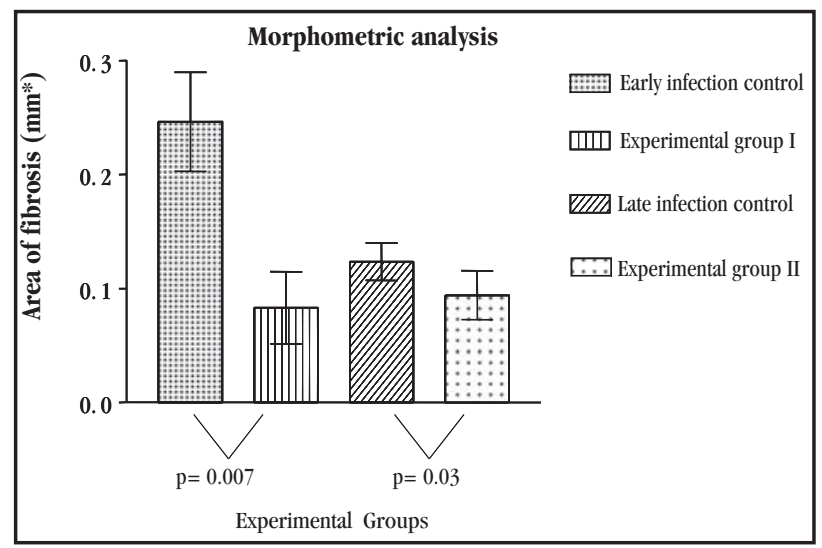

Figure 2 - Effect of partial bepatectomy on Capillaria hepatica-induced septal hepatic fibrosis in rats: comparison of the degree of fibrosis during early (30 day-old) and late (90-day-old) infections, with respective controls. The differences regarding fibrosis were statistically significant $(p<0.05)$. Variations are represented as standard errors.

\section{DISCUSSION}

When experiments involving partial hepatectomy are made on diseased livers, a twofold objective is usually envisaged: to study how a particular disease can interfere with the regeneration process, and how regeneration itself can modify the morphology of a diseased liver ${ }^{7}$. It is obvious that a diseased liver becomes functionally less efficient in several respects, but the way regeneration is affected differs markedly according to the pathological process and the parameters considered, as several recent studies have revealed ${ }^{5}$.

It is only logical to suppose that the process of hepatic regeneration does not solely involve the hepatocytes, but a variety of mesenchymal cells as well. The latter are responsible for the formation of the supporting stroma, and its vascular and biliary structures, as recently demonstrated ${ }^{7}$. Therefore, it is to be expected that the pattern of hepatic fibrosis brought about by a disease, may also be changed following partial hepatectomy.
Although the results from the present investigation indicated that the quantity of septal fibrosis induced by capillariasis had decreased both in recent and late infections, 30 days after partial hepatectomy, in comparison with infected non-operated controls, there was no fundamental modification of its distribution and general appearance. Also, no modification was seen when focal parasitic lesions were compared between the hepatectomized rats and their controls. In fact, these focal parasitic lesions run an independent course with regard to systematized septal fibrosis in rat capillariasis, as a recent investigation has revealed ${ }^{4}$.

After a careful qualitative and quantitative investigation, the impression that was left was that fibrosis itself was not significantly affected in hepatectomized rats. The relative reduction in the number of fibrous septa within each microscopic field was seen to be a consequence of the increased mass of regenerated liver cells. The same phenomenon probably occurs in cirrhotic livers, in which the post-hepatectomy picture is dominated by enlarged nodules and distended and thinner fibrous septa ${ }^{7}$. Unlike in cases of hepatic cirrhosis, septal fibrosis does not disturb the hepatic circulation ${ }^{10}$, and the mortality due to this in cases of rodent capillariasis is practically zero ${ }^{1}$.

The effect of partial hepatectomy on schistosomiasis in mice seems to follow a different pathway, since a great deal of fibrosis regression was observed in the remaining liver a few days after surgery, especially when specific treatment for schistosomiasis was performed shortly before surgery (Coelho PZ et al: unpublished data).

Thus, the present experiments demonstrated that partial hepatectomy performed in rats with either 30 or 90-day-old Capillaria hepatica-induced septal fibrosis failed to induce evident changes in the intrinsic morphology and general distribution of the fibrosis, although the proportion between the fibrous septa and the number of liver parenchyma appeared significantly reduced. Therefore the effect of partial hepatectomy on a diseased liver will essentially depend on the nature of the preexisting pathological condition. The cause and duration of fibrosis, its location, and its relationship to blood vessel changes are apparently crucial in determining the outcome.

\section{REFERENCES}

1. Andrade ZA, Assis BCA, Souza MM. Capillaria hepatica: papel em patologia humana e potencial como modelo experimental. In: Coura JR (ed) Dinâmica das Doenças Infecciosas e Parasitárias, Guanabara-Koogan, Rio de Janeiro, cap. 94, p. 1121-1132, 2005.

2. Fausto N. Liver regeneration. Journal of Hepatology 32 (suppl 1): 19-31, 2000 .

3. Ferreira LA, Andrade ZA. Capillaria hepatica: a cause of septal fibrosis of the liver. Memórias do Instituto Oswaldo Cruz 88: 441-447, 1993.

4. Gomes AT, Cunha LM, Bastos CG, Medrado BF, Assis, BCA, Andrade ZA. Capillaria hepatica in rats: focal parasitic hepatic lesions and septal fibrosis run independent courses. Memórias do Instituto Oswaldo Cruz 101: 895-898, 2006.

5. Kim T-H, Mars WM, Stolz DB, Petersen BE, Michalopoulos GK. Extracellular matrix remodeling at the early stages of liver regeneration in the rat. Hepatology 26: 896-904, 1997.

6. Mann DV, Lam VM, Hjelm NM, So MMC, Yeung DKW, Matreweli C, Lau WY. Human liver regeneration: hepatic energy economy is less efficient when the organ is diseased. Hepatology 34: 557-565, 2001. 
7. Palmes D, Spiegel H-U. Animal models of liver regeneration. Biomaterials 25: 1601-1611, 2004

8. Perez-Tamayo R. Cirrhosis of the liver: a reversible disease? Pathology Annual 14: $183-213,1975$.

9. Quinn OS, Higginson J. Reversible and irreversible changes in experimental cirrhosis. American Journal of Pathology 47: 353-369, 1965.

10. Shibayama Y, Nakata K. Significance of septal fibrosis for disturbances of hepatic circulation. Liver 12: 22-25, 1992.

11. Souza MM, Tolentino Jr M, Assis BCA, Gonzalez ACO, Silva TMC, Andrade ZA. Significance and fate of septal fibrosis of the liver. Hepatology Research 35: 31-36, 2006.
12. Souza MM, Tolentino Jr M, Assis BCA, Gonzalez ACO, Silva TMC, Andrade ZA. Pathogenesis of Septal Fibrosis of the Liver. (An experimental study with a new model). Pathology, Research and Practice 202: 883-889, 2006

13. Yamamoto H, Murawaki Y, Kawasaki. Hepatic collagen synthesis and degradation during liver regeneration after partial hepatectomy. Hepatology 21: 155-161, 1995.

14. Vinicius I, Baptista AP, Barbosa Jr AA, Andrade ZA. Morphological signs of cirrhosis regression. (Experimental observations on carbon-tetrachlorideinduced liver cirrhosis in rats). Pathology, Research and Practice 201: 449-456, 2005. 